\title{
When and Why Matches are More Effective Subsidies Than Rebates
}

\author{
René Bekkers \\ ICS/Department of Sociology \\ Utrecht University, the Netherlands \\ Paper prepared for the 33d Arnova Annual Conference, Washington DC, November 17-20, \\ 2005.
}

\begin{abstract}
Donations to nonprofit organizations may be subsidized in various ways. Eckel and Grossman $(2003,2004)$ showed that subsidies of a rebate type are less effective than matching subsidies. Meier (2005) found that subsidies decrease subsequent giving when subsidies are no longer provided. This paper provides additional insights in the effects of rebates and matching subsidies for charitable donations from a field experiment with health charities. I show that the greater effectiveness of matching subsidies found in laboratory experiments with university students also occurs in a natural context among a large, nationally representative sample of the Dutch population. I also provide some evidence on why matches are more effective than rebates. Matches attract a larger pool of donors, in part because donors expect more people to make donations and 'join in'. Matches also increase the amount contributed among specific subgroups (higher educated, higher income households and large donors). Subsidies of either type do not decrease subsequent giving in a campaign for tsunami relief.
\end{abstract}

\section{Contact}

René Bekkers, ICS/Department of Sociology, Faculty of Social Sciences, Utrecht University. Heidelberglaan 2, 3584 CS Utrecht, The Netherlands. E-mail: r.bekkers@ffss.uu.nl. Phone: +3130253 1827. Fax: +31302534405.

\section{Acknowledgements}

The Netherlands Organization for Scientific Research (NWO) supported the author with a 'Veni'-grant, \#451-04-110. Data collection for this study was made possible by TNS/NIPO and the Department of Philanthropy, Vrije Universiteit, Amsterdam. 


\section{The effectiveness of matching subsidies for charitable donations}

Governments throughout the world subsidize donations by offering tax deductions. Deductions for charitable donations lower the price of giving just like a rebate in the grocery store. At the $50 \%$ income tax level, a donation of 1 euro costs only 50 cents ( $50 \%$ rebate). Evidence from laboratory experiments with small groups of students suggests that rebates are a less effective type of subsidy for charitable donations than matching programs, which generate a mathematically equivalent price reduction (Eckel and Grossman 2003, 2004). In a matching program, an independent third party matches donations to a charitable cause at a given rate (e.g., at $100 \%$, for each dollar donated the third party matches a dollar). From a rational point of view, it is strange that a $100 \%$ match increases generosity more than a $50 \%$ rebate because the price of giving is the same. The practical significance of this finding is that tax deductions may be an ineffective type of subsidy.

This possibility raises the possibility that governments replace tax deduction programs with matching programs. To inform such a policy change, however, we need answers to a series of questions. In the present paper, I will deal with three questions: (1) whether matches are really more effective than rebates; (2) why matches are more effective; (3) at which price levels and among which subgroups of the population matches are most effective.

\section{Are matches really more effective than rebates?}

There are two reasons to doubt that matches are really more effective than rebates. The first reason is that the findings of Eckel and Grossman cannot easily be generalized to everyday life situations in which people decide about giving. The experiment was conducted among a sample of university students who participated in an experiment for a show up fee, and received additional money at the beginning of the experiment that they could decide to give away. This procedure is rather far removed from the reality of decisions on charitable donations. Strictly speaking, the dictator game used by Eckel and Grossman corresponds to a situation in daily life in which we get the question whether we might want to give away some money after we unexpectedly received $\$ 10$ without having made an effort. Usually, people decide about giving away money to nonprofit organizations that they have earned on the labor or capital market. It is unknown whether matches are also more effective than rebates among 'ordinary' citizens deciding about donations outside the lab. Meier and Frey (2003) confirmed the positive effect of a matching subsidy in a field experiment with earned wealth among Swiss university students, but did not test for a rebate effect. An additional feature of the Eckel and Grossman studies is that the participants are students only. It could be that students react differently to matching and rebate subsidies than lower educated persons. I will provide a hypothesis on this difference below.

The second reason is that the difference between matches and rebates may be an 'artifact' of the procedure used by Eckel and Grossman (2003). Davis, Millner and Reilly (2005) have argued that rebates are less effective because it was not clear enough for experimental subjects that matches and rebates are mathematically equivalent. If people are made more aware that the price of giving in a $50 \%$ rebate is the same as in a $100 \%$ match, they would give the same in both situations. We call this the bounded rationality hypothesis.

Davis et al. obtain support for their hypothesis by confronting subjects with several exercises that illustrate how rebates and matches work out on the price of a gift before they have their subjects make the actual donation decisions. This procedure is problematic for two reasons. First, the experiment induces demand characteristics that call the validity of the results into question. The procedure makes it very clear to subjects that they are expected to make no difference between the rebate and matching conditions. The exercise sends the message 'do not make mistakes!' Participants in the experiment will feel that the experimenters expect them to make rational decisions, and will act accordingly in order not to disappoint the 
experimenters. A second problem with the procedure used by Davis et al. is that it creates an experimental situation which is very different from everyday situations in which people decide about giving to nonprofit organizations. In ordinary life, donors do not complete a series of exercises before making a donation. The usual fundraising campaign confronts them with a request for a donation and only one type of subsidy.

While the procedure used by Davis et al may not be valid, the bounded rationality hypothesis may still be valid. I will use a different technique to test the bounded rationality hypothesis that does not induce demand characteristics. I rely on a cognitive proficiency test to measure people's capability to understand how a subsidy affects the price of giving. If the bounded rationality hypothesis is true, we should find that:

H2. The difference between matches and rebates is more pronounced among people with lower levels of cognitive proficiency (bounded rationality hypothesis).

Note that this hypothesis implies that matches are even more effective among persons with lower levels of education than among students, because students will on average have higher levels of cognitive proficiency.

\section{Why are matches more effective than rebates?}

Eckel and Grossman $(2003,2004)$ suggest that matches are more effective than rebates because donors experience a match as an additional gift, while a rebate is not always viewed as such. The match buys a higher donation to the charity at no cost to the donor. They argue that offering a rebate generates a competitive orientation, while offering a matching amount generates a cooperative orientation. We call this the framing hypothesis. Donors experience a matching subsidy from a third party as somebody else 'joining in' who might otherwise not have contributed. Matching programs raise the expectation of prospective donors that others are also donating more strongly than rebate subsidies. ${ }^{i}$ However, the framing hypothesis has not been tested explicitly. The purpose of this paper is to do conduct such a test. If the framing hypothesis is correct, we should find that

H3. The difference between matches and rebates is due to higher expectations about the donations of others under a matching subsidy (framing expectations hypothesis).

\section{When are matches more effective than rebates, and for whom?}

A third question that I address in the present study is at which price levels and among which subgroups of the population matches are most effective. Generally speaking, the effectiveness of subsidies for giving depends on (a) the ability of the subsidy to attract new donors, who would not have donated without the subsidy; (b) the ability to increase the amount donated among donors. The framing hypothesis does not discriminate between these alternatives. Meier and Frey (2004) argue that the matching subsidy appeals only to those who would have donated anyway and increases their donations, but only when the proportion matched is high enough (e.g., 50\%). To see this, consider the evidence from psychology that external incentives for prosocial behavior often destroy intrinsic motivation (Deci and Ryan 1985; Frey 1997). When donors receive a subsidy for giving, they can no longer attribute their giving to altruistic motives. In that case, donors who have altruistic motives for giving may reduce their giving because giving would endanger their altruistic self-identity. This is called the 'motivational crowding-out effect'. At lower subsidy levels, Meier and Frey argue, a matching program may actually lower the amount donated when the motivational crowdingout effect outweighs the price effect. This leads to the following hypotheses:

H4. The effect of matches increases with the level of subsidy.

The arguments put forward by Meier and Frey about motivational crowding out also point to the importance of recognizing the heterogeneity among donors. Subsidies may have 
different effects among different subgroups of donors. Specifically, those who have altruistic motives for giving will respond less strongly to a subsidy than those with 'warm glow' motives for giving.

H5. Subsidies for giving increase giving less strongly among persons with more altruistic motives for philanthropy (altruistic self-identity hypothesis).

H6. Subsidies for giving increase giving more strongly among persons with joy of giving motives for philanthropy (joy of giving hypothesis).

The prospective design of the Giving in the Netherlands Panel Survey enables a detailed study of the effectiveness of subsidies for giving among subgroups of the population because data on annual donations in previous years is available, as well as a wealth of other information on donors' socio-demographic characteristics and social values. I do not offer a priori hypotheses on the differential effects of matches and rebates among subgroups of the population. We may subsidize donations even more effectively if we know whether and how the effectiveness of matches varies with the price of giving and with characteristics of donors. This knowledge can be used to target matching programs at specific groups of donors, disregarding other types of donors who would not be affected by the type of subsidy.

\section{Do subsidies undermine subsequent giving?}

Finally, there is some concern about the possibility that subsidies reduce subsequent giving. If donors have received a subsidy for donations, but get no subsidy on other occasions, they may be less likely to give because the subsidy reduced their intrinsic motivation for giving. Meier (2005) found evidence for such a spoiling effect of matches on subsequent giving in the same context involving the same charity (University funds). I will test whether subsidies also reduce giving in other contexts, expecting:

H7. Subsidies for giving reduce giving on subsequent occasions where subsidies are not provided.

\section{Data and Methods}

\section{Testing the effectiveness of subsidies in a survey field experiment}

To study the effectiveness of matching and rebate subsidies in a natural context, we designed a field experiment among respondents in the 'Giving in the Netherlands Panel Survey' (GINPS, Schuyt and Gouwenberg 2005). The GINPS is a biennial survey on philanthropy and volunteering conducted by the Vrije Universiteit Amsterdam. The respondents receive a reward for participation in the survey. I study which proportion of these earnings the respondents give away under different types of subsidy.

Participants. 861 respondents took part in the experiment after completing the questionnaire of the second wave of the Giving in the Netherlands Panel Survey (GINPS), in May 2004. ${ }^{\text {ii }}$ The GINPS uses Computer Assisted Self Interviewing (CASI) through the World Wide Web. The first wave was completed by a random sample of 1,707 respondents from the Dutch population. The experiment was conducted after the second wave was completed. We use data on personal characteristics of the participants from both waves 1 and 2 (2002 and 2004). The respondents are a representative sample of the Dutch population with regard to age, gender, level of education and region of residence. ${ }^{\text {iii }}$

Procedure. By participating in the GINPS, respondents earned a reward, proportional to the amount of time it took them to complete the survey. The reward was given in the form of 'points', which corresponded to an amount in Euros. The monetary value of the 'points' earned was displayed after the respondents completed the survey. Then, the respondents were given the following choice (henceforth called the 'donation decision') between two alternative 
options. The first option consisted of an exchange of the points into Air Miles or vouchers for a well-known chain of shops for domestic articles, music and video products. The second option consisted of an exchange of earnings into a donation to one of three charitable causes: 'Médecins Sans Frontières' (MSF; in the US known as Doctors Without Borders), providing emergency health care in developing countries), the Aids Fund (fighting HIV/Aids, mainly through research) or the Queen Wilhelmina Fund (fighting cancer, mainly through medical research). ${ }^{\text {iv }}$

Completing the entire GINPS-questionnaire took the respondents about 45 minutes. The mean amount earned was $€ 11.08$ (\$13.35, exchange rate $\$ 1=€ 0.8295$, Nov. 62005 ). Because some respondents took more time to complete the survey than others, the amount of money involved in the donation decision differs between participants. The lowest earnings were 6.30 and the highest 15.75. Earnings were included as a covariate in all regressions because they are a measure of the strength of temptation to keep the money. ${ }^{\mathrm{v}}$ The pass rate is the amount donated by earnings.

Like in the 'dictator game' used by Eckel and Grossman (2003) the respondents could decide to give away any desired proportion of the money. Unlike Eckel and Grossman's study, the participants in the present study did not decide about a windfall endowment they received at the beginning of the experiment, but decided about money they earned by participating in the survey. Cherry, Frykblom and Shogren (2002) show that subjects playing with earned wealth are much less generous than subjects playing with endowed wealth. In a prior experiment I replicated this finding in a national sample of the Dutch population among the respondents of the first wave of the GINPS (Bekkers 2004). Having respondents decide about donations with earnings is a more valid procedure than having them decide after providing a windfall endowment because actual donations are also made with earned rather than endowed wealth.

After the actual donation decision, the respondents are asked how the average Dutch citizen would respond in the same condition. The respondents reported whether they thought the average person would have donated, and if so, how much. The expectation that others would donate was strongly related to actual donation decisions $(\mathrm{r}=.465, \mathrm{p}<.000$; Chi Square $185.89, \mathrm{df}=1, \mathrm{p}<.000)$. The expected pass rate was also strongly related to the actual pass rate $(r=.513, \mathrm{p}<.000){ }^{\mathrm{vi}}$

Nine months after the experiment, 704 of the 861 participants in the experiment $(81.8 \%)$ responded to a survey on tsunami relief giving in the aftermath of the disaster in South East Asia on December 26, 2004. The total amount donated to tsunami relief efforts served as a criterion variable for testing the hypothesis that receiving a subsidy would decrease subsequent giving. Attrition was randomly distributed over experimental conditions and was not related to earnings or donations in the experiment.

\section{Experimental design}

Respondents are placed randomly in one of the five conditions in the experiment (see table 1). In the base line condition, participants did not get a subsidy for their gifts. Conditions 2 to 5 vary the price of giving as in previous research (Davis, Millner and Reilly 2005). In condition 2, donations by the respondents are matched dollar-for-dollar by a third party (TNS/NIPO, the opinion poll research institute conducting the survey). In this condition, a donation of $€ 4$ effectively turns into a donation of $€ 8$, lowering the price of giving with $50 \%$. Mathematically, the price of giving in condition 2 is the same as in condition 4, where respondents get a $50 \%$ rebate. The matching condition parallels the 'Buy one, get one free' strategy that is used to increase sales in supermarkets. The rebate condition parallels the 'Now $50 \%$ off!' strategy that is also often used to reach the same goal. Conditions 3 and 5 are matching and rebate conditions at the .67 price level. 
Table 1. Experimental design

\begin{tabular}{lccccc} 
Condition & 1. Base line & $\begin{array}{c}2.100 \% \\
\text { match }\end{array}$ & $\begin{array}{c}3.50 \% \\
\text { match }\end{array}$ & $\begin{array}{c}4.50 \% \\
\text { rebate }\end{array}$ & $\begin{array}{c}5.33 \% \\
\text { rebate }\end{array}$ \\
\hline Match & No & $100 \%$ & $50 \%$ & No & No \\
Rebate & No & No & No & $50 \%$ & $33 \%$ \\
Price of giving $€ 1$ & $€ 1.00$ & $€ 0.50$ & $€ 0.67$ & $€ 0.50$ & $€ 0.67$ \\
\hline $\mathrm{N}$ & 165 & 173 & 184 & 180 & 159 \\
\hline
\end{tabular}

\section{Measures}

A measure of cognitive proficiency was included to test the bounded rationality hypothesis. Cognitive proficiency was measured with a vocabulary test (Gesthuizen and Kraaykamp 2002). Respondents read thirteen words in Dutch. For each word, respondents were asked to pick a synonym from a set of five other words. Strictly speaking, this measure taps verbal ability, but prior research indicates that measures of verbal ability are highly correlated with other measures of learned or 'crystallized' intelligence (Alwin 1991).

Two measures of motives for philanthropy were included to test the motivational crowd out hypothesis. All items were Likert-scales consisting of items on a five point scale (disagree completely - agree completely). Altruistic values were measured with a scale consisting of 8 items (alpha=.81) adapted from Lindeman (1995; example 'I don't like to spend time doing things for others'). Joy of giving was measured with three items (alpha $=.78$ ): 'Giving to charity gives me a positive feeling', 'Giving to charity makes me happy', 'Giving to charity makes me more happy than buying something for myself').

Included in the present study are measures for gender (female=1), age (in years), the level of education ( 7 categories, ranging from primary school only to university degree), gross yearly household income (midpoint values were used of 24 categories, ranging from $€ 2,000$ to $€ 300,000$; higher incomes were truncated), home ownership (yes=1), religious affiliation (dummy variables for Catholic, Reformed Protestant, Rereformed Protestant, or other), frequency of church attendance (the number of church visits per year), and the amount donated to nonprofit organizations in 2001 (total amount in euros).

Because the charities the participants could donate to are all in the health sector, I included measures of subjective health (ranging from 1 - poor - to 5 - very well) and health problems in one's social network (the number of chronic diseases among friends and family in the past two years).

Five measures for the relationship with charities were included as well: charitable confidence ('How much confidence do you have in charities?', ranging from 1 - none at all to 5 - very much); the number of personal and impersonal solicitations for charitable contributions in the two weeks preceding the survey; whether the respondents know the 'seal of approval' for fundraising nonprofit organizations ('CBF-keur', Bekkers 2003); and social pressure to volunteer for nonprofit organizations, indicated by agreement on a 1 (disagree completely) to 5 (agree completely) scale with the statement 'In my social environment, it is obvious to volunteer' (Bekkers and Schuyt 2005). 


\section{Results}

\section{Basic findings: replicating the matching effect}

Table 2 shows the distribution of donation decisions in the experiment. Compared to the rebate, the proportion of respondents keeping the reward completely (vs. giving away at least something) is significantly higher in the match and rebate condition at the $2 / 3$ price level $($ Chi Square $=6.747(\mathrm{df}=1), \mathrm{p}<.009)$. The difference at the $1 / 2$ price level is marginally significant (Chi Square $=3.157(\mathrm{df}=1), \mathrm{p}<.076)$. This result is not consistent with the hypothesis of Meier and Frey (2003) that matches would be more effective at a lower price of giving.

Table 3 shows the amounts donated and pass rates (the proportion of the earnings donated before subsidy) in the experiment. Both at the .67 and the .50 price level, matches generate higher amounts contributed than rebates (Anova F-statistic $=5.600(\mathrm{df}=1), \mathrm{p}<.019$; and $\mathrm{F}=4.556(\mathrm{df}=1), \mathrm{p}<.034$, respectively). Among donors, however, there are no significant differences in the amount donated (for price $=0.67: \mathrm{F}=0.083(\mathrm{df}=1), \mathrm{p}<.773$; for price $=0.50$ : $\mathrm{F}=1.367(\mathrm{df}=1), \mathrm{p}<.244)$. These results differ markedly from those obtained by Eckel and Grossman (2003) and Davis et al. (2005), who found that participants tended to contribute the same proportion of their endowment to the charity (about $50 \%$ and $40 \%$, respectively), regardless of the type of subsidy. In the present experiment, matches did increase the pass rate.

Table 2. Donations in experimental conditions $(n=861)$

\begin{tabular}{llcccc}
\hline Price & Frame $(\mathrm{n})$ & Keep all & $\begin{array}{c}\text { Donate } \\
\text { something }\end{array}$ & $\begin{array}{c}\text { Donate } \\
1-99 \%\end{array}$ & $\begin{array}{c}\text { Donate } \\
100 \%\end{array}$ \\
\hline 1.00 & No framing $(\mathrm{n}=165)$ & 64.8 & 35.2 & 32.1 & 3.0 \\
0.67 & Rebate $(\mathrm{n}=159)$ & 62.9 & 37.1 & 35.8 & 1.3 \\
0.67 & Match $(\mathrm{n}=184)$ & 48.9 & 51.1 & 46.2 & 4.9 \\
0.50 & Rebate $(\mathrm{n}=180)$ & 52.2 & 47.8 & 44.4 & 3.3 \\
0.50 & Match $(\mathrm{n}=173)$ & 42.8 & 57.2 & 52.0 & 5.2 \\
\hline
\end{tabular}

Among donors, however, pass rates are between 40 and 50\% in all conditions. Inspection of the distribution of pass rates among those who donated (see figure 1) reveal that there is a strong preference for giving exactly $50 \%$ of the earnings to charity. This result holds in all conditions (see appendix for separate figures for each condition).

Table 3. Amounts donated and pass rates in experimental conditions $(n=861)$

\begin{tabular}{llcccc}
\hline Price & Frame $(\mathrm{n})$ & \multicolumn{2}{c}{$\begin{array}{c}\text { Among all respondents } \\
\text { Amount } \\
\text { donated }\end{array}$} & Pass rate & \multicolumn{2}{c}{$\begin{array}{c}\text { Among donors only } \\
\text { Amount } \\
\text { donated }\end{array}$} & Pass rate \\
\hline 1.00 & No framing $(\mathrm{n}=165)$ & 1.71 & 15.36 & 4.86 & 43.70 \\
0.67 & Rebate $(\mathrm{n}=159)$ & 1.88 & 17.17 & 5.06 & 46.26 \\
0.67 & Match $(\mathrm{n}=184)$ & 2.64 & 24.19 & 5.18 & 47.36 \\
0.50 & Rebate $(\mathrm{n}=180)$ & 2.46 & 22.47 & 5.15 & 47.03 \\
0.50 & Match $(\mathrm{n}=173)$ & 3.19 & 29.14 & 5.58 & 50.92 \\
\hline
\end{tabular}




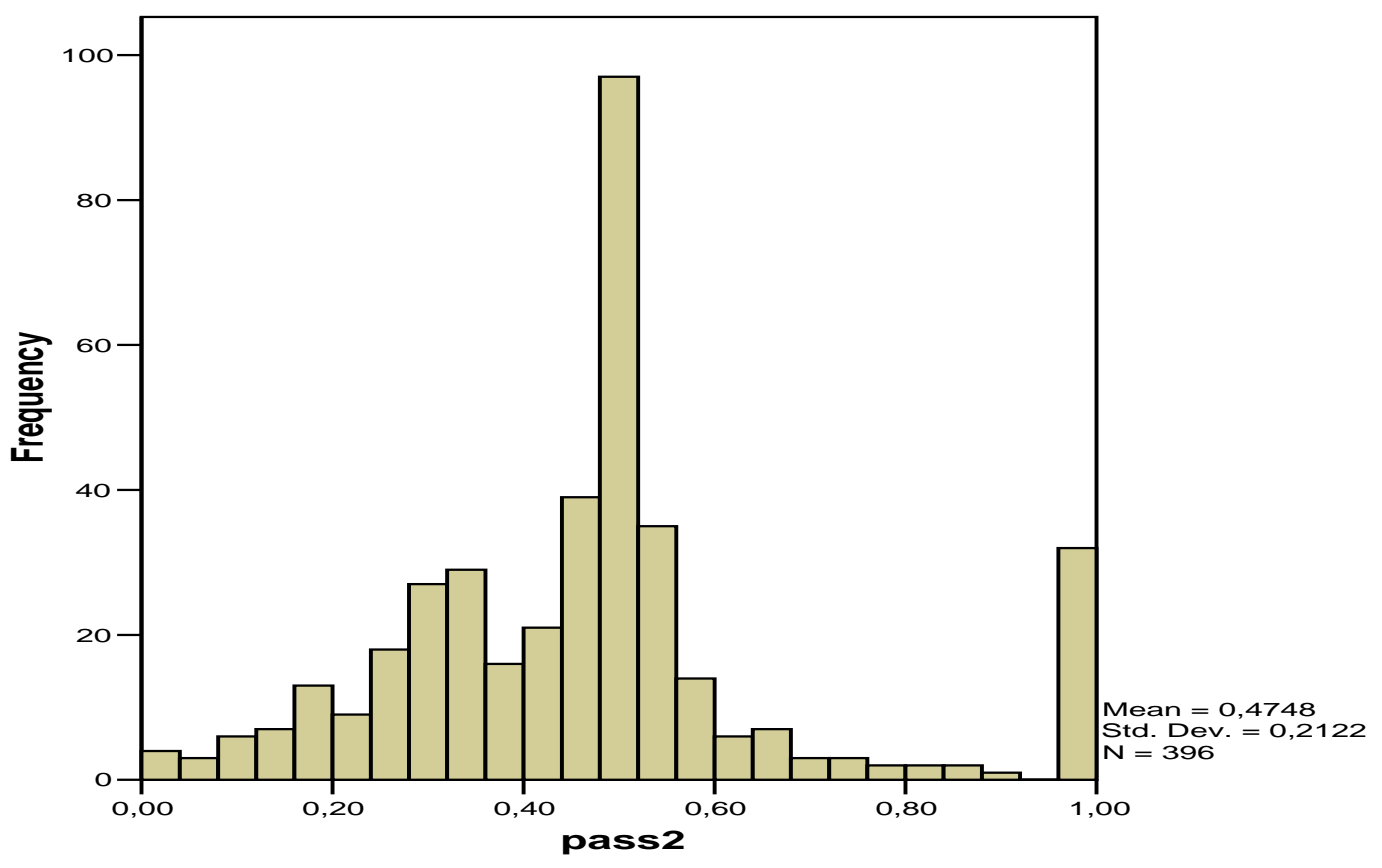

So including the zeros, the difference between matches and rebates is significant, but excluding the zeros it is not. This suggests that the match is mainly effective because it attracts more donors, but not larger donations. I will test this below using Heckman Two Stage regression models.

Recall that the framing hypothesis predicts that expectations about the contributions of others mediate the influence of the subsidy scheme. If that hypothesis is correct, we should find that the participants expect higher contributions from other participants in matching conditions than in rebate conditions. Table 4 gives little support for this prediction.

Table 4. Donations expected from others in experimental conditions $(n=861)$

\begin{tabular}{llrrrrrrr}
\hline Price & Frame & $\begin{array}{r}\text { Keep } \\
\text { all }\end{array}$ & $\begin{array}{r}\text { Donate } \\
1-99 \%\end{array}$ & $\begin{array}{r}\text { Donate } \\
100 \%\end{array}$ & $\begin{array}{r}\text { Amount } \\
\text { donated }\end{array}$ & $\begin{array}{r}€ \text { among } \\
\text { donors }\end{array}$ & Pass rate & $\begin{array}{r}\text { Pass rate } \\
\text { (donors) }\end{array}$ \\
\hline 1.00 & No frame & 28.5 & 70.3 & 1.2 & 3.27 & 4.58 & 29.16 & 40.78 \\
0.67 & Rebate & 31.4 & 65.4 & 3.1 & 3.51 & 5.12 & 31.61 & 46.10 \\
0.67 & Match & 19.0 & 78.8 & 2.2 & 3.59 & 4.44 & 33.28 & 41.10 \\
0.50 & Rebate & 23.9 & 71.7 & 4.4 & 3.81 & 5.01 & 35.21 & 46.26 \\
0.50 & Match & 18.5 & 79.2 & 2.3 & 3.84 & 4.71 & 34.94 & 42.87 \\
\hline
\end{tabular}

While at the .67 price level participants indeed expected more others to donate at least some of their earnings (Chi Square $=7.064, \mathrm{df}=1, \mathrm{p}<.008$ ), at the .5 price level they did not $($ Chi Square $=1.533, \mathrm{df}=1, \mathrm{p}<.216)$. In addition, they did not expect higher over all contributions in matching conditions ( $F$-values in Anovas at price $=.5, \mathrm{~F}=.080, \mathrm{df}=1, \mathrm{p}<.778$; at price $.67, \mathrm{~F}=.011, \mathrm{df}=1, \mathrm{p}<.918)$. This is due to the fact that those who expected that others would give away at least some of their earnings, expected that a rebate would increase the amount donated more strongly than a rebate (at least at price $.67, \mathrm{~F}=6.017, \mathrm{df}=1, \mathrm{p}<.015$; at price $=.5, \mathrm{~F}=1.272, \mathrm{df}=1, \mathrm{p}<.280$ ). In other words, the participants expected the match to be more effective in getting people to give than a rebate, but only at a lower subsidy, while at the same time they expected the contributions of others to be lower. Thus, the respondents 
thought that other people would be rather insensitive to price changes as well as framing effects. This makes it unlikely that expectations about the behavior of others mediate the influence of matching subsidies.

\section{Multivariate regression models: testing hypotheses}

Table 5 reports further evidence on the effects of matches and rebates on giving using a Heckman two stage regression model (Heckman 1979; for an application to charitable giving, see Smith, Kehoe and Cremer 1995). Stage 1 of this model relates the type of subsidy to the likelihood that people gave anything. Stage 2 of the model relates the type of subsidy to the proportion of the earnings donated, conditioning on the effect of matches on whether the respondents give at all. The results in model 1 reveal that matches increase the likelihood of a donation more strongly than rebates as well as the pass rate. Of course, a lower price also increases giving. Earnings do not affect giving in either stage.

\section{No support for bounded rationality hypothesis}

Model 2 reveals that matches are equally effective in promoting the likelihood of giving as well as the amount donated among people with varying levels of cognitive proficiency. This finding contradicts the bounded rationality hypothesis. The main effect of cognitive proficiency is positive in both stages: those with higher levels of cognitive proficiency are somewhat more likely to give, but most importantly, if they give, they give a higher proportion of their earnings. ${ }^{\text {vii }}$

Table 5. Heckman Two Stage regression of donations testing the bounded rationality hypothesis and the framing hypothesis $(n=861)$

\begin{tabular}{|c|c|c|c|c|c|c|}
\hline & \multicolumn{2}{|c|}{ Model 1} & \multicolumn{2}{|c|}{ Model 2} & \multicolumn{2}{|c|}{ Model 3} \\
\hline & Whether & Rate & Whether & Rate & Whether & Rate \\
\hline \multirow[t]{2}{*}{ Match } & $* * .275$ & $* * .080$ & $* .359$ & $* .105$ & $* .257$ & $* * * .093$ \\
\hline & $(.094)$ & $(.028)$ & $(.155)$ & $(.048)$ & $(.103)$ & $(.023)$ \\
\hline \multirow[t]{2}{*}{ Price } & $*-1.162$ & $*-.370$ & $*-1.103$ & *-.339 & (*)-1.174 & $*-.293$ \\
\hline & $(.561)$ & $(.168)$ & $(.564)$ & $(.167)$ & $(.612)$ & $(.137)$ \\
\hline \multirow{2}{*}{ Earnings } & -.039 & -.014 & -.032 & -.016 & .032 & .001 \\
\hline & $(.036)$ & $(.010)$ & $(.036)$ & $(.010)$ & $(.038)$ & $(.008)$ \\
\hline \multirow[t]{2}{*}{ Cognitive proficiency } & & & (*).240 & $* * * .118$ & & \\
\hline & & & .134 & $(.045)$ & & \\
\hline Match $*$ cognitive & & & -.129 & -.040 & & \\
\hline proficiency & & & $(.178)$ & $(.056)$ & & \\
\hline Expectation that others & & & & & $* * * 1.291$ & -.006 \\
\hline donate & & & & & $(.206)$ & $(.060)$ \\
\hline Expected amount & & & & & $* * * 1.225$ & $* * * .752$ \\
\hline donated & & & & & $(.274)$ & $(.063)$ \\
\hline $\begin{array}{l}\mathrm{N} \text { (censored, } \\
\text { uncensored) }\end{array}$ & 358 & 338 & 358 & 338 & 358 & 338 \\
\hline Chi Square (df) & $* * * 14$ & (3) & $* * * 26$ & $3(5)$ & $* * * 17$ & $78(5)$ \\
\hline Independence LR test & $* * * 2$ & & $* * *$ & .55 & $* * *$ & .00 \\
\hline
\end{tabular}


Limited support for the framing expectations hypothesis

Model 3 reveals that expectations mediate only a small part of the influence of a matching subsidy, as suggested by table 4 . The expectation that others will donate strongly increases the likelihood that people will give, and also increases the pass rate. However, controlling for expectations about the donations of others does little to reduce the difference between matching and rebate subsidies. The effect of a matching subsidy on the likelihood of donating weakens a little (from $.275, \mathrm{p}<.003$ to $.257, \mathrm{p}<.013$ ), but remains significant. A more positive the expectation about the amount that others will contribute strongly increases the amount contributed, but not the likelihood of making a contribution at all. ${ }^{\text {viii }}$

\section{Increasing marginal effects of price reductions only for rebates}

Table 6 reveals that $100 \%$ matches were not more effective than $50 \%$ matches, which is in contrast with the prediction from standard economic theory in hypothesis 4 . The result also stands in contrast with findings reported by Meier and Frey (2004), who found that matches became more effective at higher levels. For rebates, however, we do find the expected pattern: $50 \%$ rebates were more effective than $33 \%$ rebates.

Table 6. Tobit regression of donations testing effects of matches at varying price levels $(n=696)$

\begin{tabular}{lrlll}
\hline & \multicolumn{2}{c}{ Model 1 } & \multicolumn{2}{c}{ Model 2} \\
& Coeff. & S.e. & Coeff. & s.e. \\
\hline Match & .138 & $.042^{* * *}$ & & \\
Price & -.604 & $.255^{*}$ & -.085 & .058 \\
$50 \%$ match & & & -.122 & $.058^{*}$ \\
$50 \%$ rebate & & & -.241 & $.062^{* * *}$ \\
$33 \%$ rebate & & & -.020 & .016 \\
Earnings & -.020 & .016 & .354 & $.183(*)$ \\
Constant & .530 & $.223^{*}$ & 358 & 338 \\
\hline N (censored, uncensored) & 358 & 338 & $* * * 17.69(4)$ \\
\hline Chi Square (df) & $* * * 17.54(3)$ & $* * * .0174$ \\
Pseudo R Square & $* * * .0172$ &
\end{tabular}

Participants in base line condition excluded. Reference category: $100 \%$ match condition.

A Tobit specification is used instead of Heckman model due to convergence problems.

\section{Motivational crowding in effects rather than crowding out effects}

Table 7 shows effects of joy of giving and altruistic values in matching conditions in order to test the hypotheses on crowing out of intrinsic motivation. The results reject the hypotheses based on the theory of motivational crowd out. In contrast to the joy of givinghypothesis, the effect of joy of giving was not stronger in the two subsidy conditions than in the no-subsidy condition. Moreover, joy of giving did not promote giving in the rebate conditions, while it did promote giving in the base line condition and the matching condition. The effect of altruistic values also did not vary with subsidies as predicted by the altruistic self-identity hypothesis. The effect of altruistic values was even stronger in the rebate condition than in the no-subsidy condition. When offered a rebate, respondents with stronger altruistic values were more likely to give away at least something, while altruistic values did not promote giving when offered a matching subsidy or no subsidy at all. This pattern clearly runs counter to the motivational crowding out hypothesis. 
Table 7. Effects of joy of giving and other regarding preferences $(n=861)$

\begin{tabular}{lcrrrrr}
\hline & \multicolumn{2}{c}{ No subsidy } & \multicolumn{2}{c}{ Match } & \multicolumn{2}{c}{ Rebate } \\
& Whether & Pass rate & Whether & Pass rate & Whether & Pass rate \\
\hline Joy of giving & $(*) .197$ & -.047 & $* * .200$ & .022 & .047 & -.017 \\
& $(.117)$ & $(.041)$ & $(.067)$ & $(.018)$ & $(.076)$ & $(.022)$ \\
Altruistic values & .068 & .018 & .082 & .014 & $* .152$ & .018 \\
& $(.111)$ & $(.033)$ & $(.072)$ & $(.020)$ & $(.076)$ & $(.031)$ \\
\hline n (censored,uncens.) & 107 & 58 & 164 & 193 & 194 & 145 \\
Chi Square (df) & $2.12(3)$ & \multicolumn{3}{c}{$6.07(3)$} & & $1.68(3)$ \\
Independence test & 0.00 & $* * * 15.34$ & 0.00 \\
\hline
\end{tabular}

Price and earnings also included; effects not shown.

Table 8. Multinomial logit of donations on personal characteristics

\begin{tabular}{|c|c|c|c|c|c|c|}
\hline & \multicolumn{2}{|c|}{$1-45 \%$} & \multicolumn{2}{|c|}{$45-55 \%$} & \multicolumn{2}{|c|}{$55-100 \%$} \\
\hline & Coeff. & s.e. & Coeff. & s.e. & Coeff. & s.e. \\
\hline Female & -.636 & $.302 *$ & -.070 & .330 & .166 & .403 \\
\hline Female * match & 1.101 & $.433 *$ & .189 & .435 & -.404 & .539 \\
\hline Age & -.001 & .011 & .007 & .012 & .017 & .013 \\
\hline Age $*$ match & -.011 & .015 & -.001 & .015 & -.003 & .017 \\
\hline Townsize & -.000 & .001 & -.000 & .001 & -.000 & .001 \\
\hline Townsize ${ }^{*}$ match & -.000 & .002 & -.000 & .001 & .001 & .002 \\
\hline Level of education & -.042 & .149 & .039 & .162 & .020 & .212 \\
\hline Education $*$ match & .472 & $.218^{*}$ & .036 & .222 & .386 & .283 \\
\hline BA Degree & -.365 & .667 & -.474 & .689 & .843 & .860 \\
\hline Degree * match & -1.793 & $.959(*)$ & -.042 & .955 & -2.120 & $1.161(*)$ \\
\hline Donations in 2001 & -.009 & .049 & .142 & $.066^{*}$ & .033 & .069 \\
\hline Donations $*$ match & .137 & $.082(*)$ & .002 & .087 & -.010 & .091 \\
\hline Income (ln) & -.589 & $.300^{*}$ & -.106 & .350 & -.674 & $.390(*)$ \\
\hline Income $*$ match & .071 & .428 & .032 & .444 & 1.113 & $.522 *$ \\
\hline Own home & .052 & .340 & -.237 & .369 & .772 & .496 \\
\hline Own home $*$ match & .114 & .488 & .022 & .480 & -.469 & .628 \\
\hline Catholic & .447 & .397 & -.053 & .472 & -.228 & .605 \\
\hline Catholic $*$ match & .604 & .567 & .116 & .635 & .522 & .782 \\
\hline Reformed & .451 & .471 & .318 & .527 & .542 & .581 \\
\hline Reformed $*$ match & -.325 & .659 & -.274 & .681 & -.819 & .857 \\
\hline Rereformed & .349 & .599 & .198 & .583 & -.523 & .840 \\
\hline Rereformed $*$ match & -1.207 & .869 & -.421 & .758 & -.322 & 1.042 \\
\hline Other religion & -.079 & .599 & -.701 & .658 & .376 & .623 \\
\hline Price & -1.042 & 1.295 & -4.067 & $1.309 * *$ & -1.501 & 1.590 \\
\hline Match & -1.152 & 1.878 & .480 & 1.929 & -3.680 & 2.309 \\
\hline Earnings & .049 & .092 & -.100 & .090 & -.220 & $.106^{*}$ \\
\hline Constant & 1.434 & 1.711 & 2.811 & 1.871 & 1.477 & 2.098 \\
\hline
\end{tabular}

Pseudo R Square .0718; LR Chi $121.01(\mathrm{df}=78) \mathrm{p}<.0013$ 


\section{Differential effects of matches among specific groups}

Table 8 reports a multinomial logistic regression analysis of donations on sociodemographic characteristics of the respondents in the experiment. The model allows for a test of the influence of matches among specific groups on making donations of small parts of the earnings, about half of the earnings, or more. A multinomial specification allows for a more detailed analysis of the effect of matches on different levels of generosity.

Matches are equally effective among different age groups, among persons with different religious affiliations ${ }^{\text {ix }}$, among home owners and those renting a home, and among residents of towns with different sizes. However, the effect of matches did vary with gender, level of education, income, and prior donations.

While females are less likely to donate a small amount than males, matches reverse the pattern: females are more responsive to matches than males. ${ }^{\mathrm{x}}$ Higher educated persons are more responsive to matches than lower educated persons, but this trend reverses at the highest level of education. Those who hold a bachelor degree actually reduce their giving when they receive a matching subsidy. Large donors in 2001 were more likely to donate half of their earnings in the experiment than small donors, regardless of the type of subsidy. Matches were more effectively promoting small donations among large donors. While persons in higher income households were less likely to donate both a small as well as a major part of their earnings, matches increased the likelihood of donating more than half of the earnings at higher income levels.

Matches reduce giving from identification motives

Table 9 reports a multinomial logistic regression analysis of donations on attitudes towards fundraising nonprofit organizations and experiences with health problems.

Table 9. Multinomial logit of donations on attitudes to giving

\begin{tabular}{lrlrlrl}
\hline & \multicolumn{2}{c}{$1-45 \%$} & \multicolumn{2}{c}{$45-55 \%$} & \multicolumn{2}{c}{$55-100^{\circ}$} \\
& Coeff. & S.e. & Coeff. & s.e. & Coeff. & s.e. \\
\hline Confidence & .270 & .280 & .802 & $.246^{* * *}$ & .513 & $.278\left(^{*}\right)$ \\
Confidence * match & .183 & .290 & -.412 & .312 & .239 & .380 \\
Solicitations & -.095 & .110 & -.101 & .122 & -.092 & .141 \\
Solicitations * match & .058 & .157 & -.118 & .169 & -.013 & .200 \\
Social pressure & .071 & .161 & .516 & $.184^{* *}$ & .443 & $.215^{*}$ \\
Pressure * match & .209 & .228 & -.335 & .237 & -.311 & .286 \\
Know seal & .152 & .438 & -.401 & .351 & -.022 & .402 \\
Know seal * match & .152 & .438 & .623 & .456 & .507 & .545 \\
Talk about giving & .466 & .288 & -.169 & .319 & .142 & .378 \\
Talk * match & -.827 & $.384^{*}$ & .007 & .397 & -.437 & .489 \\
Subjective health & .414 & $.169^{*}$ & .086 & .199 & .085 & .229 \\
Health * match & -.416 & $.235\left(^{*}\right)$ & -.189 & .253 & .180 & .301 \\
Health problems & .008 & .100 & .068 & .115 & .161 & .126 \\
Problems * match & .132 & .138 & -.022 & .149 & -.318 & $.190\left(^{*}\right)$ \\
Price & -.198 & 1.270 & -3.679 & $1.310^{* *}$ & -2.006 & 1.588 \\
Match & 1.420 & 1.430 & 3.567 & $1.541^{*}$ & 1.047 & 1.864 \\
Earnings & -.012 & .084 & -.148 & $.085\left(^{*}\right)$ & -.235 & $.100^{*}$ \\
Constant & -3.798 & $1.460^{*}$ & -1.490 & 1.614 & -1.610 & 1.870 \\
\hline Pseudo R Square 0587; LR Chi $99.04(\mathrm{df}=51) \mathrm{p}<0001$ & & & &
\end{tabular}


Because the three charities that benefited from donations in the experiment were health charities, experiences with health problems in one's own life or in one's close social circle are relevant. Those who know people with health problems may be more likely to give in the experiment because they identify more easily with the (ultimate) recipients of their gifts. Previous research shows that giving increases with one's own health (Bekkers 2005), and with knowing people with health problems (Meijer, Bekkers and Schuyt 2005). The results in table 9 reveal that matches were less effective than rebates in generating small donations among those in better health, and less effective in generating large donations among those with more health problems in their social network. Matches were also less effective than rebates in generating small donations among those who discuss giving to charities more often. It seems that matches reduce giving among those who are more able to identify with recipients of their gifts. Table 9 also shows that the effect of matches is no different among those with different levels of confidence in charities, exposure to fundraising attempts, and awareness of the monitoring system for fundraising organizations.

\section{Subsidies promote Tsunami Relief giving}

Table 10 shows how the offer of a subsidy for donations in the experiment are related to subsequent giving, i.e. giving in response to the tsunami disaster. In contrast to the result reported by Meier (2005), receiving a subsidy in the experiment did not decrease subsequent giving to tsunami relief efforts. Moreover, respondents who were placed in the $33 \%$ rebate condition in the experiment even gave more than respondents in the base line condition, who had received no subsidy.

Table 10. Tobit regression of amount donated in tsunami relief campaign

\begin{tabular}{|c|c|c|c|c|c|c|}
\hline & \multicolumn{2}{|c|}{ Model 1} & \multicolumn{2}{|c|}{ Model 2} & \multicolumn{2}{|c|}{ Model 3} \\
\hline & Coeff. & s.e. & Coeff. & s.e. & Coeff. & s.e. \\
\hline Match $100 \%$ & .021 & .222 & .059 & .300 & -.460 & .344 \\
\hline Match 50\% & -.042 & .218 & .019 & .277 & -.452 & .315 \\
\hline Rebate $50 \%$ & .101 & .213 & -.119 & .258 & -.366 & .296 \\
\hline Rebate $33 \%$ & .512 & $.223 *$ & .604 & $.261 *$ & .359 & .292 \\
\hline Earnings & .382 & $.057 * * *$ & .331 & $.057 * * *$ & .332 & $.057 * * *$ \\
\hline Match $100 \% *$ donated & & & -.044 & .362 & -.241 & .372 \\
\hline Match $50 \% *$ donated & & & .027 & .345 & -.220 & .363 \\
\hline Rebate $50 \% *$ donated & & & .619 & $.338(*)$ & .577 & $.357(*)$ \\
\hline Rebate $33 \% *$ donated & & & -.264 & .367 & -.312 & .392 \\
\hline Joy of giving & & & .015 & .133 & .013 & .132 \\
\hline Joy of giving $*$ match & & & .475 & $.186^{*}$ & .515 & $.185^{* *}$ \\
\hline Joy of giving $*$ rebate & & & -.006 & .186 & -.005 & .184 \\
\hline Altruistic values & & & .423 & $.136^{* *}$ & .426 & $.134 * *$ \\
\hline Altruistic values $*$ match & & & -.320 & $.192(*)$ & -.346 & $.191(*)$ \\
\hline Altruistic values $*$ rebate & & & -.065 & .190 & -.064 & .189 \\
\hline Expected donations & & & & & -.111 & $.045^{*}$ \\
\hline Expected $*$ match & & & & & .220 & $.069 * * *$ \\
\hline Expected $*$ rebate & & & & & .127 & $.067(*)$ \\
\hline Chi Square (df) & $* * * 5$ & $.10(5)$ & $* * * 94$ & $.70(15)$ & $* * * 105$ & $30(18)$ \\
\hline Pseudo R Square & & 164 & & 292 & & \\
\hline
\end{tabular}


Model 2 adds interactions between experimental conditions and behaviour, because Meier (2005) found that the detrimental effect of matches was stronger in a low subsidy condition (i.e., 50\%) than in a high subsidy condition (i.e., 25\%). The present analysis shows very different results: rebates and matches did not decrease giving more strongly among those who had made donations in the experiment. If anything, those who had donated in response to a $50 \%$ rebate gave more in response to the tsunami relief campaign.

Model 2 also includes interactions between the type of subsidy and joy of giving and altruistic values. If motivational crowd out took place after the experiment, it should reduce giving to the tsunami campaign among those who give for altruistic reasons, while it should increase giving among those who give for the 'warm glow'. The analysis provides some support for motivational crowd out among those who were offered a match, but not among those who were offered a rebate. Matches increase giving among those who report a stronger joy of giving. This is important because joy of giving in itself does not promote tsunami relief giving. For altruistic values, the pattern is the reverse: persons with stronger altruistic values give more to tsunami relief, but not when they had been offered a matching subsidy in the experiment.

Finally, model 3 adds interactions between the type of subsidy and the generosity expected of others in the experiment. The analysis reveals that subsidies - and matches more strongly than rebates - promoted giving more strongly among those who held more positive expectations about the generosity of others. Including these interactions, the offer of a $33 \%$ rebate in the experiment no longer had a significant effect on tsunami relief giving. ${ }^{\mathrm{xi}}$ These results indicate that subsidies promote subsequent giving only among those who held more positive expectations about other people's generosity. These results square nicely with the finding of Shang and Croson (2005) that more positive expectations about other's generosity not only increase current giving, but also giving on subsequent occasions when subsidies are no longer provided. Shang and Croson experimentally induced expectations, providing potential donors with information about the behaviour of others.

\section{Conclusion}

This paper investigates four questions: (1) whether the same pattern of results of obtained in previous research with lab experiments among small samples of university students also hold in a natural context; (2) whether the greater effectiveness of matches holds for all types of donors; (3) when and why matches are more effective than rebates; (4) whether subsidies undermine subsequent giving.

The answer to the first question is clearly 'yes'. The stronger effectiveness of matching subsidies also occurs in a large sample of the Dutch population $(n=1,030)$ in a natural context. The participants in the present study decided about the donation of a reward earned previously by filling out the questionnaire of the Giving in the Netherlands Panel Survey. By having the participants decide about earned wealth I improve the ecological validity of the 'dictator game' used in experimental economics (Cherry, Frykblom and Shogren 2002). The participants could donate their earnings in any desired proportion to one of three popular health charities. In a baseline condition, donations were not subsidized. In the rebate condition, an independent third party (the polling institute) offered the participants a rebate for donations. In the matching condition, the third party offered the participants a matching donation to the charity of their choice. I tested rebates against matches at two price levels, generating a 50\% and 33\% price reduction for donations. At both price levels, I find that matches increase donations more than rebates, but the effect is more pronounced at a price reduction level of $50 \%$.

The answer to the second question is less clear. I found that matches are more effective than rebates partly because donors expect that matches will attract a larger number 
of donations by others in the matching conditions. This finding is consistent with the framing hypothesis that Eckel and Grossman offered as an explanation for their findings. They argue that offering a rebate generates a competitive orientation, while offering a matching amount generates a cooperative orientation. Donors experience a matching subsidy from a third party as somebody else 'joining in' who might otherwise not have contributed. Matching programs raise the expectation of prospective donors that others are also donating more strongly than rebate subsidies. In addition, donors may perceive the donations of others as a signal that giving is the appropriate course of action. On the other hand, donors also expect smaller sized donations from others. That is why expectations do not fully explain the superiority of matches over rebates. Clearly, further research is needed to understand why matches generate higher donations than rebates.

My findings are inconsistent with the bounded rationality hypothesis offered by Davis, Millner and Reilly (2005), who argue that differential framing is not the reason for the observed difference but a failure to see the equivalence of the two conditions. I find no evidence that donations by more intelligent persons in matching and rebate conditions are more similar than donations by less intelligent persons in the two framing conditions.

Matches are more effective than rebates mainly because they attract a larger pool of donors, not because they generate higher amounts donated. When donations are matched by a third party, a group of donors makes donations who would have elected not to donate when donations are subsidized with a (mathematically equivalent) rebate. However, among specific groups of the Dutch population, matches also increase the amount contributed more strongly than rebates. I find that matches are particularly effective in increasing the amount donated among the higher educated, among higher income households, and among households making larger donations to charities. These findings support the argument that the use of matches as an alternative means for subsidizing charitable donations will generate higher contributions. I also find evidence that a rebate is less effective when the price reduction is low (33\% instead of 50\%). In contrast to the results obtained by Meier and Frey (2004), the relative effectiveness of a matching program does not vary with the size of the price reduction. In contrast with the altruistic self-identity hypothesis and the joy of giving hypothesis, subsidies did not undermine intrinsic motivation for giving.

The answer to the fourth question is clearly 'no'. Matching subsidies offered in the experiment did not decrease giving nine months later in response to the tsunami disaster. A small rebate $(33 \%)$ increased tsunami relief giving nine months after the experiment.

In sum, matches are more effective than rebates among three groups in the population that are very important for philanthropy: large donors, the higher educated, and higher incomes. Households with higher levels of education and household income give more than household with lower levels of education and income. Controlling for the amount donated in 2001, matches are still more effective than rebates among these groups. This is an important result: it suggests that matches can be used to increase giving among these groups even further.

\section{Discussion}

There could be alternative reasons why matches are more effective than rebates that have little to do with the expectations about the behaviour of others. One reason could be that matches benefit a nonprofit organization directly, while rebates do so indirectly by transferring money to the donor making a contribution. Thus, the match makes it more evident that the third party is also sponsoring the cause. This may have the psychological effect of focusing the donor's attention on the benefits of a donation to the cause. A rebate, in contrast, focuses the donor's attention on the costs of the gift to herself. In the present experiment it is impossible to test this hypothesis. Future work should focus on this. ${ }^{\text {xii }}$ 


\section{References}

Alwin D. F., 1991. "Family of origin and cohort differences in verbal ability". American Sociological Review 56:625-638.

Andreoni, James and Lise Vesterlund. 2001. "Which is the Fair Sex? On Male-Female Differences in Altruism.” Quarterly Journal of Economics, 116:293-312.

Bekkers, R. 2003. "Trust, Accreditation, and Philanthropy in the Netherlands". Nonprofit \& Voluntary Sector Quarterly, 32, 596-615.

Bekkers, R. (2004). 'All-or-Nothing Dictator Games: A Field Experiment.'

Bekkers, René. \& Schuyt, Theo N.M. 2005. 'And Who is Your Neighbor? Explaining the Effect of Religion on Charitable Giving and Volunteering.' Journal for the Scientific Study of Religion.

Cherry, Todd L.; Frykblom, Peter; and Shogren, Jason F. 2002. "Hardnose the Dictator." American Economic Review, 92: 1218-21.

Davis, David D., Millner, E.L. and Reilly, R.J. 2005. "Subsidy schemes and charitable contributions: a closer look.” Experimental Economics, 8(2): 85-106.

Deci, Edward L. and Ryan, Richard M. 1985. Intrinsic Motivation and Self-Determination in Human Behavior. New York: Plenum Press.

Eckel, Catherine C. and Grossman, Philip J. 2003. "Rebate versus matching: does how we subsidize charitable contributions matter?” Journal of Public Economics, 87: 681-701.

Eckel, Catherine C. and Grossman, Philip J. 2004. "Giving to Secular Causes by the Religious and Nonreligious: An Experimental Test of the Responsiveness of Giving to Subsidies”. Nonprofit and Voluntary Sector Quarterly, 33: 271-289.

Frey, Bruno S. 1997. Not Just for the Money: An Economic Theory of Personal Motivation. Cheltenham: Edward Elgar.

Bruno S. Frey \& Stephan Meier, 2004. "Social Comparisons and Pro-social Behavior: Testing "Conditional Cooperation" in a Field Experiment." American Economic Review, 94:17171722.

Gesthuizen, M. \& Kraaykamp, G. (2002). Verbal ability of low-educated people in the Netherlands: the downside of educational expansion. The Netherlands' Journal of Social Sciences, 38: 191-211.

Heckman, James 1979. "Sample selection bias as specification error". Econometrica 47, 15362 .

Lindeman, Ellen 1995. Participatie in vrijwilligerswerk. Amsterdam: Thela Thesis. 
Meier, Stephan 2005. "Do Subsidies Increase Charitable Giving in the Long Run? Matching Donations in a Field Experiment". Working Paper, Institute for Empricial Research in Economics, University of Zurich, Switzerland.

Meier, Stephan and Bruno S. Frey. 2004. "Matching donations: subsidizing charitable giving in a field experiment." Mimeo, University of Zurich, August 20, 2003.

Meijer, May-May, Bekkers, René and Schuyt, Theo N.M. 2005. Uit een goed hart? De Hartstichting en haar donateurs. Amsterdam: Department of Philanthropy, Vrije Universiteit.

Schuyt, Theo N.M. and Gouwenberg, Barbara M. 2005. Geven in Nederland 2005: Giften, Sponsoring, Legaten en Vrijwilligerswerk The Hague: Elsevier Overheid.

Shang, Jen and Croson, Rachel. 2005. "Field Experiments in Charitable Contribution: The Impact of Social Influence on the Voluntary Provision of Public Goods."

Smith, V.H., M.R. Kehoe and Cremer, M.E. 1995. "The Private Provision of Public Goods: Altruism and Voluntary Giving". Journal of Public Economics 58:107-26. 
Appendix - Pass rates in experiment

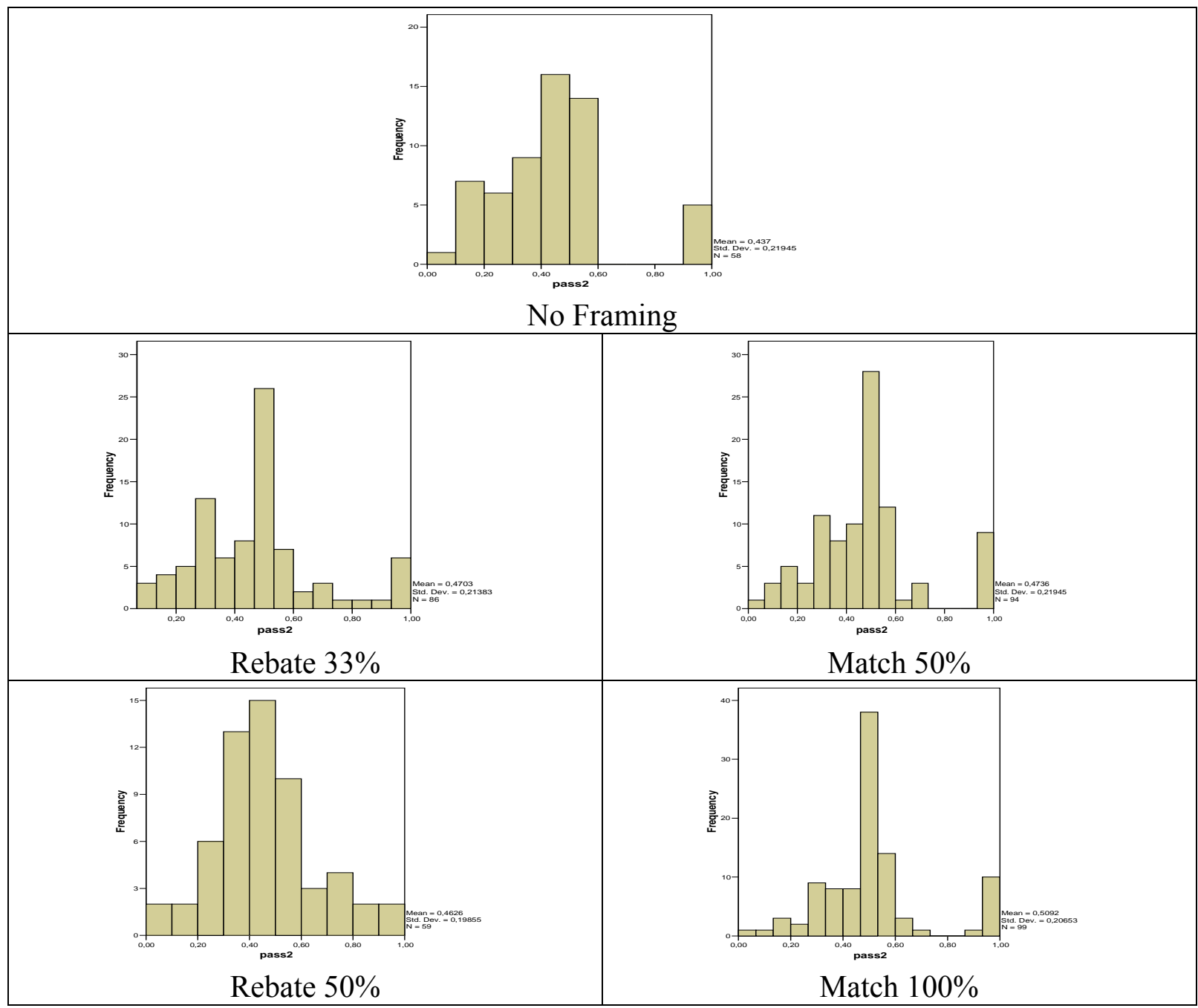

Tobit regressions of donations on characteristics of respondents

\begin{tabular}{|c|c|c|c|c|c|c|}
\hline & \multicolumn{2}{|c|}{ No subsidy } & \multicolumn{2}{|c|}{ Match } & \multicolumn{2}{|c|}{ Rebate } \\
\hline & Coeff. & s.e. & Coeff. & s.e. & Coeff. & s.e. \\
\hline Income & -.006 & $.003 *$ & .001 & .001 & -.002 & .001 \\
\hline Catholic & .221 & .140 & .095 & .076 & .037 & .090 \\
\hline Reformed & .380 & $.163^{*}$ & .044 & .089 & .125 & .104 \\
\hline Rereformed & .343 & $.179(*)$ & -.056 & .114 & .054 & .131 \\
\hline Other religion & .162 & .261 & .014 & .175 & -.148 & .187 \\
\hline Church attendance & -.006 & $.002 *$ & -.001 & .001 & -.001 & .002 \\
\hline Cognitive proficiency & .020 & .024 & .015 & .011 & .032 & $.016^{*}$ \\
\hline Empathy & -.257 & $.107 *$ & .031 & .058 & -.071 & .068 \\
\hline Joy of giving & .109 & .072 & .064 & $.037(*)$ & .084 & .056 \\
\hline Responsibility & .217 & $.088 *$ & .064 & .043 & .091 & $.035^{*}$ \\
\hline Charitable confidence & .106 & .071 & .097 & $.040^{*}$ & .116 & $.042 * *$ \\
\hline $\mathrm{n}$ & \multicolumn{2}{|c|}{165} & \multicolumn{2}{|c|}{357} & \multicolumn{2}{|c|}{339} \\
\hline Pseudo R Square & \multicolumn{2}{|c|}{.1368} & \multicolumn{2}{|c|}{.0552} & \multicolumn{2}{|c|}{.0589} \\
\hline
\end{tabular}




\section{NOTES}

${ }^{\mathrm{i}}$ In addition, donors may perceive the donations of others as a signal that giving is the appropriate course of action. Potters, Sefton and Vesterlund (2004) show that donations by others in a sequential setting may 'set the example'. Because the subjects in our experiment decided independently and we did not give our subjects information about the behaviour of others in the experiment, the leadership phenomenon cannot account for the effect of the matching subsidy.

${ }^{\text {ii }}$ For reasons unknown, 216 respondents were unable to participate in the experiment. This was a random group. None of the predictors of giving in the analyses was related to participating in the experiment. An additional random group of 169 respondents were excluded from the analyses below because they made different type of decision that is difficult to compare with previous studies (an 'all-or-nothing' decision, either keeping the earnings or giving them away completely; see Bekkers 2004).

iii Respondents were drawn randomly from a pool of 72,000 respondents who regularly participate in surveys through the Internet. Persons in this pool were originally drawn randomly from the population register, and were invited in a letter to participate in surveys. Prospective participants who did not possess a suitable personal computer with internet connection were provided with one. Data for the present study were collected through the internet. Because there was no interviewer present when the respondents completed the GINPS-questionnaire and decided about donating their earnings, experimenter demands are unlikely to play a role in donation decisions. In drawing the sample, special care was taken to avoid sample bias with regard to Internet use by stratification with regard to age, gender, and geographic region. More details on design, sampling and questionnaires are given in Schuyt, 2003:225-8.

iv Donations may have been constrained by the fact that only one of three charities could be chosen. However, the three charities are well known in the Netherlands. In terms of fundraising income, the Queen Wilhelmina Fund is one of the largest charities in the country (Central Bureau of Fundraising 2003). In addition, two of the three charities are active in the medical research sector, which is a very common cause for donations in the Netherlands because many health charities organize door-to-door collections with high response rates (Schuyt 2003). In the first wave of the GINPS, almost seven out of ten (69.4\%) of the respondents reported donations by their household to health causes in the past year.

${ }^{\mathrm{v}}$ Donation decisions were automatically stored in a secure electronic database on the Internet, as were the responses in the GINPS-questionnaire. The complete survey session was held without interference by a human interviewer or experimenter. After the donation decision was made, an automatic e-mail message was sent to the respondents confirming their decision (e.g., 'We have transferred an amount of $€$ xxx to your bank account number $x x x^{\prime}$ ). This procedure bears similarity to a single blind-procedure in ordinary dictator games. It is not double blind because respondents may believe that their responses and donation decisions can be traced by data analysts by matching the data obtained in the survey session with the e-mail address used for soliciting participation.

${ }^{\mathrm{vi}}$ Interestingly, the respondents expected the average citizen to be more generous than they were themselves. Among those who kept their earnings, 58\% expected the average citizen to give away at least something.

${ }^{\text {vii }}$ A multinomial logit analysis distinguishing three categories of pass rates (1-45\%, 45-55\%, 55-100\%) revealed that the interactive effect of cognitive proficiency and subsidies was most pronounced on giving $55 \%$ or more.

viii The effect of earnings changes signs in model 3 because expectations interact with earnings. Additional analyses (available from the author) reveal that a more generosity expected from others affected own generosity more strongly when the price of giving was lower. The effects of expectations did not interact with receiving a subsidy or the type of subsidy. A multinomial logit analysis revealed that the effects of expectations were strongest on making a large donation (pass rate $>55 \%$ ). It should be noted that expected contributions were not manipulated in the present study. They may have been shaped by a 'justification effect': participants may expect others to do as they do in order not to make their own behavior appear as 'deviant' (Meier and Frey 2004).

${ }^{\text {ix }}$ As in Eckel and Grossman (2004), donations in the present analysis were not higher among those with various types of religious affiliation than among the non-religious. Additional analyses including the frequency of church attendance revealed positive effects of being Catholic, Reformed, or Rereformed and a negative effect of church attendance on the probability of making a small donation (1-45\%).

${ }^{\mathrm{x}}$ Additional analyses reveal that males more often made donations than females in the no-subsidy conditions, but not in the experimental conditions in which the price of giving was reduced. Thus, females were more sensitive to the price of giving than males. This result is at odds with the evidence from a lab experiment reported by Andreoni and Vesterlund (2001), who found that males increased their giving more as the price of giving was was reduced, while females did not.

${ }^{\mathrm{xi}}$ In a model including expectations but not interactions of expectations with subsidies, expectations had no effect, and the effect of the $33 \%$ rebate was still significant. This shows that expectations do not mediate the effect of subsidies on subsequent giving. 


\begin{abstract}
${ }^{\text {xii }}$ Another reason why matches are more effective than rebates may be the expectation of transaction costs. In ordinary life, rebates often involve filling out forms to get your money back. Or donors may doubt that they will actually get the rebate. This possibility is ruled out by the experimental design. Donors did not have to do anything in order to get the rebate.
\end{abstract}

